\title{
Ação entre Amigos: Relações entre Banqueiros do Bicho e Milícias nas Disputas Político-Econômicas da Contravenção
}

\section{Action between Friends: Relations between Bankers of the Animal's Game and Militias in the Political-Economic Disputes}

\section{Rômulo Bulgarelli Labronici}

Universidade Federal Fluminense, Niterói, Rio de Janeiro, Brasil

\section{RESUMO}

O mercado de jogos de apostas ilegais no Rio de Janeiro possui diversas formas de ser abordado. Neste trabalho, busca-se compreender e analisar a relação entre dois grupos distintos, porém complementares, denominados de banqueiros do jogo do bicho e milicianos que administram com mãos de ferro o monopólio desse mercado. Disputas por esse controle envolve a produção de alianças voláteis que se consolidam e se desfazem à medida que os interesses político-econômicos se voltam para a dominação territorial de partes da cidade. Respeitando estruturas hierárquicas e disciplinares, o mercado adquiriu formas empresariais de manter-se lucrativo a partir de valores comuns entre tais os grupos. Além disso, as relações de parentesco e afinidade explicitam o modo com o qual os controles do jogo encontram-se circunscritos entre pequenos grupos inserindo a prática do apadrinhamento como peça inerente a estrutura macropolítica desse mercado.

Palavras-chave: Jogo do bicho, Milícia, Contravenção, Caça-níquel, Mercado.

\section{ABSTRACT}

The illegal gambling market in Rio de Janeiro has several ways to be approached. In this work, we seek to understand and analyze the relationship between two distinct but complementary groups, called bankers of the animal game [jogo do bicho] and militiamen who manage the market monopoly with an iron hand. Disputes over this control involve the production of volatile alliances that consolidate and dissolve as political-economic interests turn to the territorial domination of parts of the city. Respecting hierarchical and 
disciplinary structures, the market has acquired entrepreneurial ways to remain profitable based on common values among such groups. In addition, kinship and affinity relations explain the way in which the game controls are circumscribed between small groups of affinity, inserting the practice of sponsorship as an inherent part of the macro-political structure of this market.

Keywords: Animal game, Militia, Misdemeanor, Slot machine, Market.

\section{INTRODUÇÃ̃o}

Na manhã de terça-feira, no estacionamento de um centro comercial no bairro do Recreio dos Bandeirantes na zona Oeste da cidade do Rio de Janeiro, Shanna Garcia se dirige a um salão de beleza como faz todas as semanas, sempre no mesmo horário. Nesse momento, um segundo carro se aproxima do seu e de dentro dele uma pessoa sentada no carona abaixa o vidro e atira contra ela ao menos três vezes. Atingida por dois tiros, consegue se proteger atrás da porta de seu carro blindado e foge do local com vida e sem ferimentos graves ${ }^{1}$. Os disparos realizados de dentro do carro impediram que a polícia pudesse encontrar cápsulas deflagradas no local, já que essas caíram dentro do veículo. Indícios de um elevado grau de especialização dos atiradores. Em depoimento à Delegacia de Repressão às Ações Criminosas Organizadas (Draco), em 2016, ela diz que teria recebido uma ameaça do ex-cunhado, Bernardo Bello Barboza, que seria o administrador das cerca de 14 mil máquinas caça-níqueis e 10 mil pontos ${ }^{2}$ de jogo do bicho que teriam um lucro de até $\mathrm{R} \$ 200$ mil por dia, na região central e zona sul da cidade do Rio de Janeiro ${ }^{3}$.

1 Disponível em: https://odia.ig.com.br/rio-de-janeiro/2019/10/5808458-caca-niqueis--jogo-do-bicho-e-lucro-de-r--200- mil-por-dia-em-disputa-na-familia-garcia.html.

$2 \mathrm{O}$ termo "pontos" são a denominação para cada local de venda da loteria do jogo do bicho. Cada qual possui uma dinâmica própria. Apesar de uma estrutura semelhante com a venda do mesmo jogo, cada ponto contém algumas variáveis importantes. De início, o número de funcionários trabalhando em cada ponto pode variar entre um e outro. Podem existir pontos com um, três até mesmo dez funcionários trabalhando de uma só vez e suas funções podem ser as mais distintas. O número de trabalhadores é dado em função do movimento de fregueses em cada localidade. Os horários de funcionamento dos pontos também variam. Um ponto pequeno geralmente "abre" entre as 8 e 9 da manhã e "fecha" às cinco e meia da tarde, com exceção dos que realizam jogo na "corujinha", jogos corridos após às $21 \mathrm{~h}$. Os locais preferenciais para a instalação dos pontos são também as esquinas próximas do comércio local (LABRONICI, 2012, p.68-69).

3 Disponível em: https://extra.globo.com/casos-de-policia/filha-de-bicheiro-contou-policia-que-temia-ser-alvo-de-vinganca-do-ex-cunhado-24006570.html. 
Shanna é filha de Waldomiro Paes Garcia, conhecido como "Maninho do Salgueiro", que controlava o jogo do bicho em diversas áreas da zona sul e norte da cidade, possuindo sob seu controle milhares de máquinas caça-níqueis. Em 2004, o contraventor saía de uma academia no bairro de Jacarepaguá quando foi morto com tiros de fuzil e pistola. Maninho estava acompanhado do filho de 15 anos no momento de sua morte. O rapaz foi ferido, mas sobreviveu ${ }^{4}$. As investigações da Subsecretaria de Inteligência de Segurança apontaram para o envolvimento no assassinato de um policial miliciano, ligado a uma comunidade do bairro de Jacarepaguá. Ele teria agido a mando de outro chefe do bicho, motivado pela invasão de Maninho ao seu território inserindo máquinas caça-níqueis em bares e restaurantes da Barra da Tijuca. A inserção de Maninho teria rompido acordos de fronteiras do jogo do bicho e desencadeado o conflito 5 .

Após a morte de Maninho, Shanna foi nomeada inventariante do espólio do pai, mas teve atuação questionada por sua irmã gêmea, Tamara, que a acusa de ter vendido diversos bens da família - incluindo cavalos de corrida - sem que os demais membros fossem notificados. Além disso, Tamara reclama que a irmã não teria depositado os rendimentos do espólio, incluindo o recebimento de aluguéis de diversos apartamentos.

Um segundo evento trágico na família de Shanna ocorreu com seu tio, Alcebíades Paes Garcia, o "Bid", irmão de Maninho. O contraventor foi morto na terça-feira de carnaval de 2020 durante a madrugada por dois homens encapuzados, na Barra da Tijuca, quando voltava do desfile das escolas de samba. Testemunhas contaram que, no momento da execução, os atiradores que estavam encapuzados ficaram de campana ${ }^{7} \mathrm{em}$ um carro preto à espera da vítima, quando um deles se aproximou da van onde estava Bid e disparou com uma arma de grosso calibre. Em torno 40 tiros de fuzil foram disparados, segundo alguns relatos ${ }^{8}$. O banqueiro ${ }^{9}$ foi

\footnotetext{
4 Entretanto, em 2017 o filho de Maninho, Waldomiro Paes Garcia Júnior, ou "Mirinho", foi sequestrado e morto. No inquérito finalizado em abril do mesmo ano, a Divisão de Homicídios (DH) concluiu que um grupo havia sido contratado para sequestrar, extorquir e, depois do pagamento de 100 mil reais, matar o rapaz de 27 anos no bairro de Vargem Pequena. O sequestro ainda está sob investigação, sendo considerado como fachada para o assassinato do filho do contraventor. Disponível em: https://oglobo.globo.com/rio/imagens-mostram-momento-em-que-filha-do-bicheiro-maninho-baleada-no-recreio-video-24004622.
}

5 Disponível em: https://www.terra.com.br/noticias/brasil/policia/rio-bicheiros-usam-milicianos-para-matar-adversarios-diz-policia,64c81054a250b310VgnCLD200000bbcceb0aRCRD.html

6 Em algumas grafias encontra-se "Bide".

7 "Ficar de campana", no jargão militar, significa ficar de vigia, ser responsável por ficar na guarda de algo ou de alguém.

8 Disponível em: https://g1.globo.com/rj/rio-de-janeiro/noticia/2 020/02/25/em-rede-social-irmao-de-contraventor-maninho-exibia-viagens-ao-exterior-para-cacar.ghtml.

9 O termo banqueiro, ou banqueiro do bicho, populariza-se no início do século XX e é utilizado aos então donos do jogo do bicho. Pois, um banqueiro, no bicho, é a pessoa que "banca" a aposta dos demais. Isso se dá pela forma 
atingido por disparos na cabeça, no peito e em um dos braços, sendo o único atingido dentro da van que transportava outras pessoas. "Bid" - que além de ter se tornado um dos nomes fortes da família após a morte de seu irmão - havia afirmado que Shanna o ameaçou, tendo apontado a sobrinha como a mandante da morte do pecuarista Rogério Mesquita, em 2009, que administrava o Haras da família, um dia depois de ter procurado a Delegacia de Homicídios (DH) para dizer que estava sendo seguido. A partir de denúncia do Ministério Público, Shanna foi ao banco dos réus como a mandante do atentado, entretanto, a justiça a absolveu.

$\mathrm{Na}$ época, o chefe da segurança de Shanna, Adriano Nóbrega, ex-capitão do Batalhão de Operações Especiais da Polícia Militar do Rio de Janeiro (Bope), era suspeito do assassinato de Mesquita, tendo inclusive já respondido pela tentativa de homicídio anterior do pecuarista. Apontado como matador de aluguel e integrante do Escritório do Crime (grupo suspeito no envolvimento na morte da vereadora Marielle Franco e seu motorista Anderson Gomes ${ }^{10}$ ), Adriano foi morto na Bahia em 2020, após uma operação policial ainda sob investigação ${ }^{11}$.

Após a morte de "Bid", em depoimento, Shanna volta a acusar o ex-cunhado Bernardo e afirma não confiar nos policiais da Delegacia de Homicídios (DH) pois ainda não havia sido descobertos os mandantes dos assassinatos dos membros de sua família. Além disso, ela afirma que sua desconfiança se dá pelo fato de que muitos policiais trabalharem para contravenção ou receberem propina do jogo do bicho ${ }^{12}$.

Essa complexa trama familiar, que bem poderia ter saído das páginas de contos de Nelson Rodrigues (1959), surgiu nas páginas dos principais jornais do país, cujos desdobramentos, muitas vezes trágicos, se dão em meio a disputas de poder, recursos financeiros e controle da contravenção das regiões dominadas pelo então poderoso banqueiro do jogo do bicho Miro, um dos integrantes da cúpula do bicho e avô de Shanna. A narrativa abordada se deu a partir de re-

como o pagamento da premiação do jogo ocorre com a entrega dos valores integrais aos vencedores, independentemente do número de ganhadores existentes. Segundo a opinião de alguns autores, os primeiros banqueiros seriam, em sua maioria, imigrantes - árabes, portugueses, espanhóis, entre outros. Em geral, a exploração do bicho era conjugada a outras atividades legais, como mercearias e até mesmo loterias regulamentadas e corridas de cavalo (CAVALCANTI, 1940, apud DAMATTA; SOÁREZ, 1999).

10 A morte de Marielle representou um ponto de inflexão nas investigações das milícias. A apuração da atuação dos matadores profissionais ganhou impulso e desvendou laços de Adriano e outros milicianos com outros braços do crime organizado, além de suas conexões políticas. A então Procuradora Geral Raquel Dodge sustentou que a polícia estadual está contaminada e "às milícias espalhadas pela cidade, seus homicídios mediante pagamento, participação de policiais ou ex-policiais, em um cenário de plena impunidade" que, segundo ela, "nem a intervenção federal no Estado do Rio em 2018 conseguiu reverter”. Disponível em: https://brasil.elpais.com/ brasil/2019/11/02/politica/1572728129_887853.html.

11 Revista Época. Disponível em: https:/epoca.globo.com/rio/a-vida-a-morte-de-adriano-da-nobrega-24247527. 12 Reportagem SBT. Disponível em: https://www.youtube.com/watch?v=w3KcpDNzX3M. 
portagens e relatos jornalísticos com o intuito de desnudar algumas das relações entre dois grupos tradicionais conhecidos como bicheiros e milicianos. Ao contrário do que se apresenta em um primeiro momento, esses grupos não estão necessariamente em lados opostos, mas, como pretendo demonstrar, encontram-se organizados em grupos de aliança e afinidade de modo a consolidar e fortalecer os controles sobre os mercados de apostas ilegais na cidade. Assim, a partir de etnografias e trabalhos realizados no âmbito do jogo do bicho (SOÁREZ,1992; SOARES, 1993; DAMATTA; SOÁREZ, 1999; MAGALHÃES, 2011; LABRONIC, 2012; CHAZKEL, 2014) objetiva-se aqui evidenciar as estruturas de poder e controle da loteria do bicho, bem como as inter e intra-relações evidentes entre esses grupos e que explicitam as porosidades nas fronteiras do crime. As alianças e afinidades interpessoais são, nesse mercado ilegal, formas historicamente estabelecidas para manutenção da segurança, estabilidade e administração de conflitos entre seus atores para a continuidade desta loteria. Situações supracitadas de conflitos e disputas entre estes indivíduos foram apresentados como situações sociais (GLUCKMAN, 2009) de modo a explicitar e evidenciar os dramas imbuídos nas estruturas de funcionamento de tais organizações e na produção de alianças voláteis que se consolidam e se desfazem de acordo com os interesses e objetivos de tais grupos. Alianças estas que se estabelecem para a manutenção e controle territorial dos lucrativos pontos de jogo e máquinas caça-níqueis espalhadas pelas ruas e comércio local na cidade do Rio de Janeiro e com isso, fortalecer o poder político-econômico de alguns atores frente às práticas da contravenção. Tais relações de parentesco e afinidade evidenciadas nos conflitos explicitam o modo com o qual os controles do jogo encontram-se circunscritos entre pequenos grupos de afinidade inserindo a prática do apadrinhamento como peça inerente a estrutura macropolítica do jogo do bicho.

As distintas formas com que a prática da loteria do bicho pode ser apreendida dificultam uma abordagem simplificada de crime ou atividade ilegal em si, relacionada a um tipo de atividade inerente ao universo das práticas tidas como "crime organizado". Entendida também como uma atividade com um traço lúdico do imaginário cultural a partir de representações entre animais, sonhos e eventos cotidianos, insere o jogo em uma tradição mágico-religiosa no âmbito de uma diversão inofensiva da cultura popular. Os antropólogos Roberto DaMatta e Elena Soárez (1999) apontam para explicações que alavancaram a popularidade do jogo tomando-o como uma prática cujos significados estariam de acordo com a estrutura da tradição brasileira. Uma tradição com um status ambíguo de prática arraigada/difundida e de atividade proibida/ estigmatizada, entre o empreendimento capitalista, o parasitismo e a corrupção do Estado. Pensado assim a partir de uma dupla face, a de "vício" e de "jogo inocente", na interface de uma sociedade tradicional e uma nação moderna na qual seríamos constituídos. 
Além dele, o aspecto da informalidade, ou questões relacionadas ao trabalho informal nas zonas urbanas (DE SOTO, 1980; RABOSSI, 2004; PIRES, 2010), atribuída aos trabalhadores do bicho ganham evidência nas ruas e nas interações entre o jogo e seu público de aficionados que se encontram diariamente nas ruas, bares e esquinas da cidade. Trabalho que é realizado por indivíduos integrantes das classes populares na venda de bilhetes de sorte distribuídos em pontos estratégicos nos mais variados centros urbanos com grande movimento de fregueses em potencial. Essa distribuição reflete na organização macropolítica do jogo através da distribuição de pontos de determinados banqueiros em regiões da cidade sob seu domínio. Tais apreensões levam o jogo a ser dotado com uma gestão diferencial de "ilegalismos" (FOUCAULT, 2001; 2007) a partir de distintos regimes de tolerância. A porosidade entre a relação formal e informal, legal e ilegal colocam o jogo do bicho em uma situação aparentemente ambígua, tal como é explícito em seus jogos de poder, relações de força e campos de disputa. Como aponta a socióloga Vera Telles, "ilegalismos" adquirem formas de gestão:

(...) que se deslocam, se redefinem e se refazem conforme a vigência de formas variadas de controle e também, ou sobretudo, os critérios, procedimentos e dispositivos de incriminação dessas práticas e atividades, oscilando entre a tolerância, a transgressão consentida e a repressão conforme contextos, microconjunturas políticas e relações de poder que se configuram em cada qual. (TELLES, 2009, p. 120).

A transitividade do jogo do bicho, mascarada por uma moralidade consensual, permite que a lei seja aplicada seletivamente. O jogo do bicho permanece, assim, inserido neste "regime de tolerância", e contribui para a discussão sobre os modos de como as leis operam. É preciso deixar claro que os ilegalismos não são imperfeições ou lacunas na aplicação das leis, eles compõem os jogos de poder e se distribuem conforme se diferenciam. O que, segundo o próprio Foucault (1994), constituem “os espaços protegidos e aproveitáveis em que a lei pode ser violada, outros em que pode ser ignorada, outros, enfim, em que as infrações são sancionadas" (p. 716). Assim, mesmo com uma tipificação penal de contravenção, a ambiguidade atrelada ao jogo abre margem para diferentes atribuições morais e que muitas vezes mascaram os seus jogos de poder, relações de força e campos de disputas político-econômicas imanentes ao controle desse mercado de apostas.

Deste modo, se torna evidente aqui que o "jogo do bicho" se apresenta uma categoria polissêmica que vai da tradição a ilegalidade, do capital moderno a informalidade, do carnaval aos sonhos tendo por detrás uma aura nebulosa de uma organização que não mede esforços para manter o seu poder territorial, econômico e político. Adotando formas de atuação dentro e fora 
das leis, em conjunto com a atuação de operadores do Estado que se fazem necessários para a manutenção lucrativa do jogo ilegal nas ruas e esquinas das grandes cidades. Com a atual dinâmica do controle territorial de tanto banqueiros do bicho quanto milicianos a dinâmica tende a uma sobreposição de seus controles, o que propiciam interações que acentuam laços voltados ora para uma lucratividade mútua e ora para uma crescente e potencial fonte de conflitos.

\section{"SONHAR COM REI, DÁ LEÃ0"13}

No momento em que o jogo do bicho passou a ser explorado, existia uma estrutura montada na cidade para a venda de bilhetes de loterias permitidas e não permitidas. "Os escritórios e agências lotéricas surgiam como o espaço privilegiado para a comercialização destes bilhetes, mas ao seu lado também havia uma infinidade de possibilidades para o apostador tentar sua sorte" (MAGALHÃES, 2011, p. 98). É importante ressaltar que, na maioria dos casos, as loterias foram tomadas como mais um produto a ser oferecido pelos comerciantes, sendo vendido junto com outros produtos ou serviços. A partir dos anos 1940, pode-se pensar numa competição entre banqueiros. Uma competição pautada pela lei do mais forte e com o objetivo de concentrar os pontos de jogo em torno de alguns poucos donos. Esta competição nem sempre se deu pelos meios da administração capitalista. Em alguns momentos, as balas foram o meio para se ganhar mais pontos e de acabar com a concorrência. De tal modo, o jogo se constitui enquanto um mercado ilícito, segmentado, competitivo e perigoso. Conflitos armados entre banqueiros durante as décadas de 1950 e 1960 já tomavam conta das páginas policiais do país. Os conflitos envolviam organizações de pistoleiros - chamados pela imprensa de "Sindicato do Crime" - e de suas redes familiares, numa verdadeira "sangrenta sucessão de lutas de proporções alarmantes" (O DIA, 1961, apud MISSE, 2007, p.4). Os tempos românticos do bicho não eram por isso menos violentos. Historicamente, a repressão e a tipificação penal, ao invés de coibir a atividade gerou o inverso, possibilitou a criação de um pano de fundo estruturado e organizado para a continuidade do mercado de apostas ilegais. (LABRONICI; SILVA, 2017).

A estrutura desse mercado permaneceu segmentada em territórios rivais até o final dos

13 Samba enredo da Escola de Samba Beija-Flor de Nilópolis, campeã do carnaval carioca em 1976, cuja letra homenageia o banqueiro Natal. Letra foi escrita por Neguinho da Beija-Flor e o desfile produzido pelo carnavalesco Joãosinho Trinta. 
anos 60, quando se estabeleceu a "cúpula do jogo do bicho". Movimentos de maior ou menor tensão entre banqueiros pautados por alianças voláteis, de um lado, e conflitos armados de outro, e que marcavam a representação da macropolítica dos donos do jogo. A cúpula, assim, foi criada de modo a estabilizar a aliança entre os "grandes" banqueiros da cidade. Sob a liderança inconteste de Castor de Andrade, filho de banqueiros dos anos 40 e 50, até então no controle da grande maioria de pontos em Bangu e Padre Miguel, a cúpula se organizou legalmente com a criação da Liga Independente das Escolas de Samba do Rio de Janeiro (LIESA), que começou a dirigir os grandes desfiles do carnaval carioca desde então. Sob o poder de banqueiros do bicho como Castor de Andrade, Aniz Abraão David, Luiz Drumond e Capitão Guimarães (este último que assumiu a presidência da LIESA em 1987), os desfiles de carnaval no Rio se tornaram um espetáculo caro, com gastos elevados para as escolas, mas também receitas cada vez mais polpudas se tornando uma porta à lavagem de dinheiro do jogo (CAVALCANTI, 1994) ${ }^{14}$. A Liga foi criada com o objetivo de privatizar o carnaval e deixá-lo nas mãos dos banqueiros a gestão dos recursos oriundos das vendas de ingresso, direitos de transmissão de imagem e publicidade das principais escolas de samba. Com isso, o poder público foi esvaziado e as pequenas agremiações foram enfraquecidas. (OTÁVIO; JUPIARA, 2015, p.147). A formalização selada com a cúpula do bicho faz com que atribuições de maior importância fosse dada a alguns banqueiros. Um ícone de um determinado bairro ou zona da cidade. A relação entre banqueiros e escolas de samba demonstram claramente uma influência dentro da macropolítica do jogo. Principalmente no que tange a atuação de alguns banqueiros dentro do escopo de outras atividades para além da contravenção. Como afirmaram Roberto DaMatta e Elena Soárez (1999): “(...) a imensa fortuna dos banqueiros de bicho transborda generosidade para outras atividades" (p.162). Como evidenciado anteriormente, um banqueiro de bicho possui influência econômica política e social, na qual a atuação com o carnaval se apresenta como um reflexo desta influência. De qualquer maneira, o mecenato ou a patronagem do banqueiro expande-se para outras instâncias: "Com o enriquecimento dos bicheiros, essa confiança logo se transformou em patrocínio: auxílio a obras públicas, com pessoal e empregos em troca da lealdade da população" (CAVALCANTI, 1994, p. 97). Além da grandiosa ajuda financeira às escolas de samba, e também a vários times

14 Maria Laura Cavalcanti afirma existir um verdadeiro mecenato artístico do mundo do bicho para com o mundo do samba. “(...) as escolas de samba tornaram possível uma integração positiva do bicheiro na vida da cidade. (...) Ou seja, a ação de bicheiros, através das escolas de samba, é também uma integração para as massas à vida urbana na cidade.”. (CAVALCANTI, 1994, p. 98-99). Assim, o banqueiro apresenta-se não apenas como um operador de uma contravenção, mas é também visto como uma espécie de líder comunitário que busca a todo o momento aumentar sua influência e seu prestígio perante o grupo. 
de futebol, eles investem também, no cinema, no teatro e outras atividades culturais há quase $40 \operatorname{anos}^{15}$.

Foi também a partir dos anos 1960, enquanto parte da sociedade brasileira travava uma luta contra o regime militar, que os contraventores aproveitaram para iniciar seu bote adquirindo influência ao longo dos "anos de chumbo" da ditadura civil-militar (1964-1985). Segundo fatos desvendados por uma série de reportagens entre os dias 6 e 9 de outubro de 2012 pelo jornal O Globo, (2012 apud OTÁVIO; JUPIARA, 2015, p. 11), entre os anos 1970 e 1980 os chefes do bicho oferecem um porto seguro aos setores mais radicais oferecendo uma terra de oportunidades para quem tivesse disposição e topasse ser recrutado para compartilhar o vasto conhecimento adquirido nas masmorras do regime. Assassinatos do período misturaram interesses militares e civis, envolvendo bicheiros e torturadores. Como o subtenente da reserva do exército, Ari Barbosa Torres, um dos acusados pela tortura, assassinato e ocultação do corpo do ex-deputado Rubens Paiva, desaparecido em vinte de janeiro de 1971, no auge da repressão militar. ${ }^{16}$ Amigo de infầncia do banqueiro Aniz Abraão David (Anísio Abraão), teria o ajudado a arrebatar a banca de jogo de pequenos banqueiros da Baixada Fluminense, abrindo caminho a ferro e fogo. Torres, que em um dos lados sombrios da escola de samba Beija-Flor de Nilópolis, após o desmantelamento do aparelho repressivo com a abertura política do país, foi nomeado o chefe do barracão e segurança de Anísio. Assim, em meio aos preparativos para o carnaval circulavam Policiais Militares (PMs) e Policiais Civis da ativa e da reserva, conhecidos, amigos ou seguranças do patrono e sua família. "Uma rede que protegia os negócios e era sustentada por dinheiro, tráfico de influência ou troca de favores. O carnaval não apagava a barbárie" (OTÁVIO; JUPIARA, 2015, p.74).

As lideranças do bicho, desde os municípios adjacentes da Baixada Fluminense até as zonas mais nobres da cidade foram divididas pelo controle de grandes banqueiros, que são caracterizados por serem membros da cúpula, e banqueiros menores, estando estes sob as rédeas dos primeiros, e que, em geral, possuíam menos influência e poder econômico além de necessitarem de uma permissão para trabalhar nas determinadas áreas de controle (LABRONICI, 2012). Além disso, era necessário um extraordinário senso de oportunidade, habilidade para superar uma eventual escassez de capital, adotar recurso à violência - quando necessário- e

15 Ver também: SOARES (1993, p. 145).

16 Formalmente denunciado, em 17 de março de 1987, pelo procurador-geral da Justiça Militar Francisco Leite Chaves, informado pelas listas de torturadores do grupo Tortura Nunca Mais (apud OTAVIO; JUPIARA, 2015, p. 73). 
adquirir cobertura política/policial. Este último, um dos fatores centrais para a manutenção de um andamento "estável" do jogo, criam um sistema de proteção aos agentes subordinados à alguns banqueiros. Desta maneira, a relação com o poder público se fez necessária, pois somente assim o bicho teria um ambiente "seguro" e com estabilidade para dar continuidade as apostas. A "politização da repressão" (CHINELLI; SILVA, 1993, p. 48) através de acordos, alianças e propinas que garantiam a convivência, e através de uma influência política mais ampla, foi capaz de influir na "filosofia" ou orientação geral da ação policial.

O fator de uma cobertura política através de acordos diretos com banqueiros atua em prol desta convivência aparentemente estável e pacífica entre o bicho e o poder público. Assim, estes acordos com os próprios policiais contribuem para o monopólio do jogo nas mãos de um pequeno e seleto grupo de banqueiros. Com isso evita-se a necessidade do recurso explícito direto à violência correndo o risco de estourar situações de conflitos e disputas constantes entre si. Apesar disso a estrutura do jogo ainda faz uso de um "braço armado" a serviço do chefe da organização de modo a garantir por meio da força, se for necessário, o controle de seus domínios. Como apontam Chinelli e Silva,

\begin{abstract}
A insuficiência e a precariedade da "politização da repressão", associada à ausência de um quadro normativo que permitisse definir as fronteiras entre as diferentes organizações sem recurso à força, fizeram com que, durante muito tempo, explodissem violentos conflitos que puseram em relevo a dimensão paramilitar envolvida no processo de institucionalização do jogo do bicho. Sua consolidação institucional - mesmo com permanência na "transgressão" - progressivamente reduziu a frequência e a relevância do recurso à força, até atingir o momento atual, que se caracteriza por uma pacificação aparentemente total obtida através de um acordo de cúpula que parece bastante estável e que conta com o aval implícito do poder público. (...) o braço armado perde seu antigo sentido estratégico, sendo substituído pela força econômica e política, mas preserva-se o "estilo" que contribuiu para moldar. (CHINELLI; SILVA, 1993, p. 49).
\end{abstract}

Tal dinâmica explicita uma correlação de forças entre os donos do jogo desnudando as relações de confiança e as redes de aliança essenciais para que os pontos de uma localidade permaneçam sob o controle de determinado banqueiro. Um apadrinhamento de banqueiro para banqueiro permite que os demais possam usufruir de outras áreas. Apesar das institucionalidades do jogo do bicho, com a criação da cúpula, as relações não são exclusivamente mediadas pela formalidade. A cúpula se transforma, então, no palco de discussão e deliberação das futuras ações do bicho. Antes da entrada de Capitão Guimarães, outro grande banqueiro renomado do bicho, a dinâmica de gestão do jogo imperava a desorganização e o improviso. A divisão terri- 
torial era feita na base do "daqui pra cá é meu; daqui pra cá é seu”, contou Capitão Guimarães. A partir da entrada do ex-militar, o jogo adotaria procedimentos empresariais e se informatizaria. A cúpula ganhou contornos de estado-maior e remonta a adoção de altas reuniões em lugar da palavra dada. "Antes, você podia dormir com 50 pontos e acordar sem nenhum. Reuni os banqueiros daqui e loteamos Niterói", contou Capitão Guimarães em entrevista para o jornal $\mathrm{O}$ Globo ${ }^{17}$. O dono de ponto era considerado como o corretor, que trabalhava para o chefe que ganhasse a maior comissão da "descarga".

A descarga pode ser vista também como um reflexo das dinâmicas de alianças entre os donos do jogo. Uma relação que em um primeiro momento se apresenta como puramente econômica, mas que no fundo reforça posicionamentos dominantes de um banqueiro sobre os demais. O bicheiro "Carlinhos" define de maneira precisa a forma como se dão as descargas nos pontos do bicho ao longo do tempo:

Sempre tem um que segura a descarga dos demais bicheiros. Quem começou com isso tudo era o Tio Patinhas. Ele segurava, se não todas, a grande maioria das descargas. Ganhava muito dinheiro com isso. Por isso que se chamava Tio Patinhas, tinha dinheiro pra cobrir todo mundo. Depois quando ele morreu, ele doou tudo pro Maninho, agora eu nem sei mais quem faz, acho que é o Turcão. (apud OTÁVIO; JUPIARA, 2015, p. 58).

A analogia da figura do "Tio Patinhas" entre desenho animado e banqueiro do bicho é extremamente significativa, pois remete a figura de um indivíduo dotado de extremo poder financeiro (literalmente dono de um cofre forte repleto de ouro) capaz de bancar grandes parcelas do o jogo. Ângelo Maria Longa, o Tio Patinhas, foi um dos grandes da contravenção no final da década de 70 e início de 80 . Dedicou cinquenta anos de sua vida à contravenção. Era um dos homens com maior movimento de apostas em todo o estado, com pontos em diversos bairros da zona sul do Rio de Janeiro, desde os bairros do Catete até o Leblon, em partes do Centro da cidade, Tijuca e Vila Isabel. Um dos mais ricos dos banqueiros, seus negócios eram conhecidos como "Bradesco da Contravenção". Tio Patinhas morreu no dia 16 de março de 1986, aos 76 anos, vítima de câncer, e teria apadrinhado e cedido espaço para a entrada de futuros banqueiros, como o caso de Capitão Guimarães (OTÁVIO; JUPIARA, 2015, p. 235). Assim, como afirmou o bicheiro "Carlinhos" ele foi uma figura proeminente que atuava na "descarga". As apostas, cujas premiações são maiores do que a capacidade que os pequenos banqueiros teriam de bancar, seriam repassadas para os banqueiros da descarga, e com isso, repassariam os

17 O Globo de 23 out. 1981. (apud OTÁVIO; JUPIARA, 2015, p. 139). 
riscos de grandes e polpudas vitórias no jogo que poderiam levar a uma quebra da banca. Após a morte de Maninho, como apontou Carlinhos, a descarga do Rio e Niterói foram herdadas por "Turcão", outro banqueiro pertencente à cúpula do bicho ${ }^{18}$.

A descarga assim torna-se mais do que uma necessidade econômica, e vai além de um simples seguro, ela pode ser vista como um controle obtido pelos grandes banqueiros. Além de representar uma forma de evitar um possível "derrame" ${ }^{19}$ da banca, mantendo a credibilidade que o jogo possui para com seus apostadores, esta prática pode ser observada como uma das chaves do controle sobre um determinado território onde atuam banqueiros de menor influência. Além disso, a descarga mantém a liquidez necessária de banqueiros menores conservando a confiança fundamental dos apostadores para a continuidade das apostas em um jogo que se encontra fora do escopo legal do Estado, seguindo a máxima de que: "o bicho sempre paga".

As relações de fronteira são preocupações constantes, tanto na vida de um banqueiro, quanto na dos demais trabalhadores do bicho. Ultrapassar ou explorar negócios em territórios de outros banqueiros são fontes geradoras de conflitos que podem, em último caso, levar a disputa para execuções e assassinatos, como explicitado no caso da morte do banqueiro Maninho. Assim, banqueiros dividem a cidade em uma verdadeira colcha de retalhos e loteiam regiões e zonas pertencentes a cada um, cuja distribuição dos pontos, em geral, respeita acordos previamente estabelecidos e definidos. Inicialmente, a divisão segue uma estrutura formalizada entre os já concretizados grandes banqueiros.

A distribuição dos pontos de cada banqueiro respeita a delimitação de cada território, onde cada um tem a sua área e pode distribuir, dar, vender ou conceder seus pontos para outros banqueiros a partir de regras pré-estabelecidas e formalizadas entre si. Em zonas fronteiriças esta regra pode ser mais maleável, pois pode haver pontos próximos de banqueiros diferentes. Na região central da cidade do Rio de Janeiro é onde isso é mais evidente. O bicheiro "Domingos", por exemplo, que trabalha no centro da cidade há mais de 30 anos, conta que esta região é dividida por mais de dez banqueiros diferentes. Podendo haver em uma mesma quadra uma banca $^{20}$ em cada esquina de banqueiros distintos. As zonas fronteiriças das áreas de cada ban-

18 Ver: Jornal Extra: "Bicheiro dá garantia contra apostas altas”. Disponível em: http://www1.folha.uol.com.br/ folha/brasil/ult96u 85444.shtml. Acesso em: 06 jan. 2012.

19 Termo nativo para um prejuízo ou quebra da banca.

20 No jogo do bicho, a banca é também a denominação de uma instância provedora e de suporte que dá garantia para que os bicheiros se mantenham trabalhando nas ruas. Diante de qualquer problema ocasional, não só com policiais, um bicheiro prontamente se disponibilizará a ligar para a banca para esclarecimentos ou auxílio. Lá se encontram diferentes funções, mas principalmente a de gerente que administra diversos pontos espalhados pela localidade sob seu domínio. Os tamanhos das bancas também podem ser variados podendo 
queiro não são estritamente definidas, deixando margem para o surgimento de pequenas concorrências entre pontos de diferentes banqueiros (LABRONICI, 2012, p.54).

Esta dinâmica entre banqueiros e a divisão territorial do jogo é corroborada com a fala de "Zinho", porta-voz do jogo do bicho no final da década de 1980, em entrevista para à antropóloga Simone Simões Soares, e que traz uma imagem de como a dinâmica entre banqueiros funciona:

Temos nossa cúpula, que são sete: Castor (presidente), Miro, Luiz Drummond, Turcão, Rafael Palermo, Anisio Abraão, Capitão Guimarães. Aqui estamos divididos em cinco áreas: Zona Centro, Zona Norte, Baixada e interior. Cada zona tem três representantes, são 15 representantes. Temos uma reunião todo mês com a cúpula. A cúpula não decide, quem decide é a maioria dos representantes numa votação democrática. Nossas decisões são só aqui no Rio, nós não interferimos nos outros Estados. Nossa tecnologia é a mais avançada. Aqui não aparece aventureiro. Cada um tem a sua área. Se eu quiser vender meu negócio, tenho que vender para meu vizinho. Ninguém pode vender seu ponto sem dar preferência ao banqueiro vizinho. No centro da cidade, nós temos 8 a 10 banqueiros; se ninguém estiver interessado (os vizinhos) poderá vir um outro banqueiro. Existe o respeito. Existe uma disciplina, uma hierarquia. Eu tenho quase 300 empregados. Tenho nove pontos em lojas e na rua. Cada loja tem o gerente, o caixa (carimbador), os aranhas (cambistas) e os funcionários. (SOARES, 1993, p. 75).

Grandes e pequenos banqueiros coexistem sem que a haja a possibilidade de concorrência desleal atrapalhando assim a dinâmica de suas relações. Noções de respeito, disciplina e hierarquia formam a base de sustentação de um funcionamento pacífico e lucrativo após a consolidação da cúpula. Entretanto, a criação de novos concorrentes se torna alvo de preocupação para os banqueiros já consagrados e atuantes. Em entrevista, um morador do município de Nilópolis, na Baixada Fluminense, conta ao historiador Luiz Bezerra:

Era comum em algumas ocasiões a polícia fechar um ponto de bicho que pertencia a um banqueiro determinado, e não agia nos outros pontos. Quer dizer, só pegava aquele ponto. Então se supõe que um outro estivesse bancando a polícia para ir contra o adversário, né? No concorrente, digamos assim. Não era uma situação de equilíbrio. E havia também novas pessoas querendo bancar, querendo montar ponto. Isso era comum. Normalmente, a polícia agia em cima deles, prendia, batia... Isso tudo mesmo antes de 64. (BEZERRA, 2010, p. 32).

conter a função de administração e pontos de jogatina. (LABRONICI, 2012 p. 75). 
Entretanto, não apenas de disputas se baseia a dinâmica de distribuição e divisão de pontos de jogo. O controle do jogo do bicho, em determinadas regiões, pode ser pautado por uma divisão de banqueiros que possuíam uma lógica de compra de pontos para a revenda ${ }^{21}$. A semelhança do jogo com um negócio que demanda gestão de recursos financeiros, obtenção de proteção policial e coordenação de pessoal, evidenciam as dificuldades de um banqueiro começar debaixo e se tornar bem-sucedido sem que se tenha o apadrinhamento de outro já atuante na contravenção. A concentração de pontos do jogo nas mãos dos grandes banqueiros não se deu de forma casual. Para se tornar um grande banqueiro, não bastava já ter algum envolvimento com o jogo ou ser um pequeno banqueiro. As relações entre parentes e suas redes de alianças são essenciais para um fortalecimento dos negócios. O parentesco e as redes de relações inter-pessoais de afinidade se apresentavam como uma via importantíssima de transmissão de poder e expansão dos negócios devido a impossibilidade de vincular os membros da organização por meios de relações contratuais formais, assim como estabelecer a hierarquia em estatutos legais. Sem amparo legal, relações de afinidade se tornam fundamentais a uma série de laços para a expansão de negócios ilícitos: é no corpo a corpo político que os banqueiros seguem defendendo seus negócios. Apesar disso, como ficou claro no prólogo deste texto, em muitos momentos as desavenças e conflitos de interesse ainda são resolvidas na bala.

Estas disputas criaram uma representação social sobre a figura do banqueiro que reflete até mesmo o posicionamento de trabalhadores de bicho nas ruas da cidade atualmente. O bicheiro "Zé" afirma que, em determinadas localidades, a presença de um bicheiro é considerada um anteparo contra eventuais assaltos ou roubos.

(...) a vagabundagem tem medo e não mexe com a gente não, eles acham que tem algum vigia, ou coisa parecida. Esse dinheiro todo aqui ó! [me mostrando um bolo de notas] não é nosso [referindo-se a quem trabalha nas ruas]. E se não é nosso, ele tem que ser de alguém. Quando eu trabalhava na Penha, o dono do boteco que eu trabalhava próximo vivia pedindo para eu ficar na porta do bar dele. As pessoas sabem que vagabundo tem medo de bicheiro (apud LABRONICI, 2012, p. 49).

Assim, ao longo dos pontos de jogo espalhados pela cidade não se tem a necessidade constante de uma proteção extensiva. A representação social do banqueiro do bicho vai além de um simples marginal ou fora da lei. Sua força não está inserida exclusivamente no indivíduo. As redes e influências são fatores de peso na representação de tais figuras. Tais redes de influência

21 Isso mostra o potencial econômico do jogo do bicho e a alta lucratividade envolvida. (BEZERRA, 2010, p. $34)$. 
que se voltam para a manutenção do monopólio do controle do jogo e de sua segurança voltada para uma convivência lucrativa desse mercado. O destino é o lucro e a proteção dos negócios. Como afirmou Castor de Andrade à Folha de São Paulo (1985, p. 20): “A contravenção tem um princípio. Ela é governo e não tem culpa que o governo mude toda hora".

\section{COM AS GARRAS DE FORA}

Como apontado anteriormente, as lutas e conflitos entre banqueiros pelo controle de pontos na cidade do Rio de Janeiro, historicamente, foram, segundo o sociólogo Michel Misse (2007), um importante "fator de representação social da violência na cidade, mas foi a ligação que se estabeleceu entre esse mercado ilícito e a "proteção" policial o principal responsável pela representação crescente de corrupção policial (...)” (p. 5). Essas redes sociais passavam não apenas a explorar o jogo do bicho, mas aquilo que o autor chama de "mercadorias políticas", ligado à repressão a determinados mercados. A partir deste contexto repressivo, bens públicos (pertencentes ao Estado) são apropriados por funcionários do Estado e transformados em um bem privado, que podem ser trocados por dinheiro ou favores. A mercadoria se torna política, pois o seu valor depende de uma correlação de poder e de forças entre as partes durante a transação (troca) e o seu preço é fixado a partir desta dimensão política e econômica. Assim, propinas, chantagens, extorsões e redes de proteção interligam mercados legais, ilegais, formais e informais. Tal dinâmica, explícita se complexifica e se reelabora conforme os atores sociais inseridos no jogo do bicho e grupos milicianos se voltam para a proteção e manutenção do mercado do jogo ilícito, muitas vezes encontrando-se diretamente associados a processos de administração de conflitos pautados por violência e morte. Tais grupos, denominados de milícias, estão cada vez mais se inserindo neste papel.

Atualmente, no Brasil, o termo milícia refere-se a policiais e ex-policiais (principalmente militares), bombeiros e agentes penitenciários, todos com algum treinamento militar e pertencentes a instituições do Estado, que tomam para si a função de proteger e dar "segurança" em vizinhanças supostamente ameaçadas pelo tráfico de drogas. As antropólogas Alba Zaluar e Isabel Conceição (2007, p. 91) apontam que a organização de grupos milicianos constitui um fenômeno relativamente novo no Rio de Janeiro, efeito de malsucedidas políticas de segurança pública. São militares que abusam do monopólio da violência garantida pelo Estado, que lhes fornece treinamento e armas. São agentes do estado que têm ou tiveram a função de garantir o 
cumprimento da lei, mas agem fora do escopo legal, muitas vezes contra a lei, não só para fazer da segurança um negócio lucrativo, mas também para explorar, em muitos outros empreendimentos, os mais vulneráveis entre os trabalhadores urbanos, precarizados em suas garantias legais de habitação, acesso à Justiça e proteção institucional nas localidades onde vivem. Estes grupos de policiais e ex-policiais constituem o mesmo fenômeno, denominado "grupo de extermínio" nas décadas de 1960, 1970 e 1980 na Baixada Fluminense e na zona oeste da cidade do Rio de Janeiro, onde predominavam migrantes vindos de outros estados ${ }^{22}$. A novidade está na ampliação dos negócios com a "venda" de produtos e serviços, por meio de extorsões apresentadas como proteção contra assaltos, que marcaram também o início da máfia italiana no século XIX e, posteriormente, das máfias estadunidenses. O discurso predominante sobre o surgimento e a expansão das milícias é de que elas teriam se popularizado a partir da experiência bem-sucedida na comunidade de Rio das Pedras. Segundo o sociólogo Marcelo Burgos (2002, p. 34), que primeiro estudou sobre o fenômeno, as milícias passaram a ser mais expressivas, em termos de quantidade de favelas controladas, apenas a partir dos anos 2000. Época em que taxas de segurança, o monopólio do comércio de determinados produtos e serviços e o assistencialismo não apenas já estava consolidados em Rio das Pedras, como também havia tornado essa favela famosa pela "segurança local”, "uma espécie de oásis em meio à barbárie".

É isso que se observa no fenômeno da privatização da segurança nas áreas denominadas "de risco", "de vulnerabilidade" a esquemas militarizados de poder, como os de grupos de milicianos ou de traficantes que violam os direitos de cidadania da população local. Para manter o crescente poder econômico financeiro a gestão da morte do concorrente se torna um importante instrumento de negociação. Segundo Alba Zaluar,

Não foi, portanto, apenas a preferência por um domínio mais eficaz na contenção da guerra entre comandos do tráfico e na garantia de não intervenção violenta da Polícia que provocou o crescimento irrefutável das áreas faveladas dominadas por "milícias" no Rio de Janeiro. Também o constrangimento, a invasão pura e simples das favelas, assim como a entrega delas pela associação de moradores, às vezes por meio de "venda" à organização, sem esquecer as injunções políticas de proteção dada por membros do Legislativo, contribuíram para isso. Mas é inegável que o controle e a exploração para fins lucrativos de um território, sem o amparo da lei, podem desembocar no uso abusivo da força pelas "milícias", levando-as também a matar. (ZALUAR, 2012, p. 357).

22 Além disso, o que é ainda mais grave, os milicianos vêm tentando ocupar espaços cada vez maiores nos poderes Legislativo e Executivo municipais e estaduais, construindo redes no interior do poder público, e até no Judiciário. Em 2007, as milícias dominam 86 favelas (de acordo com o mapa das milícias fornecido pela Secretaria de Segurança do Estado e pela Comissão Parlamentar de Inquérito da Alerj) e são compostas por vários grupos (ZALUAR; CONCEIÇÃO, 2007 p.91). 
Assim, as bases da milícia são grupo de extermínio, entretanto, ela se apresenta com aspectos estruturais e organizacionais mais sofisticados. Segundo o sociólogo e autor do livro Dos Barões ao extermínio: uma história da violência na Baixada Fluminense (2003), José Claudio Souza Alves, a impunidade dos grupos milicianos é decorrente da sua própria penetração nas esferas do poder público. Ou seja, o Estado não foi corrompido, nem deturpado, nem sequestrado. Não é uma ausência de Estado. O Estado é o organizador, sendo uma estrutura atuando desde a década de 1970 de maneira intocada e com o surgimento das milícias amplia-se a sofisticação da dominação econômica na atuação de tais grupos.

Os modos de operar o poder se sustentam em bases do controle territorial e econômico de certas atividades lucrativas. Entretanto, a forma de atuação não se dá de maneira homogênea entre estes grupos e a diversificação dos modos de operacionalizar e controlar as atividades em seus territórios adquirem uma discricionariedade contextual a partir dos objetivos e interesses dos agentes inseridos no poder (ZALUAR; CONCEIÇÃO, 2007; ZALUAR, 2012; CANO; DUARTE, 2012).

O mercado de jogos de caça-níqueis pode ser explicitado como uma das atividades com um alto potencial lucrativo explorado nesse contexto e que evidencia a relação mais explícita entre tais grupos milicianos e o jogo do bicho. Historicamente, tal mercado esteve no controle de banqueiros de bicho também relacionadas ao ramo da contravenção. As máquinas caça-níqueis são geralmente caracterizadas pelo seu sistema conhecido como "noteiro", no qual é possível que o apostador insira seu dinheiro (moedas ou notas) diretamente na máquina. Em geral, são acusadas de serem facilmente manipuladas e "viciadas" pelos seus operadores, deixando poucas chances para o apostador ganhar o prêmio máximo. Como diz a máxima dos jogos de azar: "a casa sempre ganha"; no mercado de máquinas caça-níqueis não é muito diferente. Segundo informou um interlocutor que trabalhou na construção de tais máquinas em galpões da Baixada Fluminense e na zona oeste da cidade, um volume específico de apostas (14 vezes o prêmio máximo) é pré-estipulado pelo operador da máquina e inserido no sistema de modo que a máquina somente "libera" o prêmio após o montante ser alcançado.

A introdução das máquinas caça-níqueis se deu a partir de uma conexão do bicho com a máfia italiana. Segundo os jornalistas Chico Otávio e Aloy Jupiara (2015, p. 134), a ambição do bicheiro Castor de Andrade - cuja importância ímpar para o mercado de jogos ilícitos já foi diversas vezes explicitada aqui - na procura por diversificação dos negócios foi fundamental para a entrada dessa tecnologia no país. Ambicioso, botou em prática um processo desenvolvimentista próprio. Essa aproximação começara no início da década de 1960, quando o capo Antônio Salamone, fugido da polícia italiana, desembarcou na cidade do Rio de Janeiro. Castor, 
de modo a adquirir favor com o alto escalão da máfia, o auxilia, utilizando de seus contatos ao longo do regime militar na década de 1970. Usufruindo de sua influência política, fez com que Salamone permanecesse no país e até mesmo conseguisse tirar a cidadania, o que seria uma impossibilidade devido ao fato de Salamone ter um mandato de prisão internacional expedido contra ele. Reconhecendo o apoio recebido, o mafioso foi um dos elos de Castor com a máfia italiana, quando, já nos anos 1980, as máquinas de jogos de azar chegaram e se espalharam pelo país. Atualmente, afirmou o bicheiro "Carlinhos", tanto as máquinas como seus pontos de jogo são focos de divisão territorial. Assim como ocorre na divisão dos pontos de jogo do bicho pela cidade, cada banqueiro possui o seu território de caça-níquel. (apud LABRONICI, 2012, p. 56).

Deste modo, territórios de banqueiros e milicianos se entrelaçam e sobrepõe fazendo com que acordos entre tais grupos sejam acionados de modo a produzir um funcionamento regular, garantindo a previsibilidade lucrativa deste mercado. Uma aliança pelo lucro é deste modo orquestrada entre estes grupos, aparentemente, distintos. A atuação em parceria na administração de máquinas de caça-níquel em territórios dominadas por grupos milicianos, conforme investigações da Polícia Civil do Rio de Janeiro ${ }^{23}$ apontam, são construídas com tais objetivos. Assim, uma parcela das apostas é adquirida por grupos milicianos sob a forma de "pedágio" com o repasse da maior parte restante aos banqueiros do bicho. Em outros casos, milicianos passam a ser os “donos" das máquinas, pagando um aluguel aos contraventores. Além disso, uma das formas que essa parceria é operada se dá através da colaboração da segurança das máquinas instaladas em bares e padarias nos territórios controlados por banqueiros. De acordo com uma reportagem do portal Terra (11 abr. 2010), o então delegado Cláudio Ferraz, da DRACO, afirma que há casos nos quais traficantes são expulsos do controle das máquinas por milicianos para entregá-las aos banqueiros do bicho. "Em algumas áreas, onde máquinas eram exploradas pelo tráfico, a milícia expulsa o bandido e chama os bicheiros para uma nova parceria", afirmou. Num mesmo sentido, em reportagem investigativa para a Revista ÉPOCA $(2020)^{24}$, os jornalistas Chico Otávio e Aloy Jupiara apontam que assim como controlam a venda de botijões de gás e a instalação de "gatonet", milicianos cobram pedágio de banqueiros pelo funcionamento de caça-níqueis em áreas sob seu controle. Entretanto, a disputa pelo controle desse mercado tem se inclinado cada vez mais na direção da milícia tomar territórios de contraventores enfraquecidos em busca do domínio da jogatina ilegal.

23 Disponível em: https://www.terra.com.br/noticias/brasil/policia/rio-bicheiros-usam-milicianos-para-matar-adversarios-diz-policia,64c81054a250b310VgnCLD200000bbcceb0aRCRD.html.

24 Disponível em: https:/epoca.globo.com/rio/ex-capitao-do-bope-promoveu-alianca-entre-milicianos-bicheiros-24275879. 
A diversificação dos mercados controlados por esses grupos começa a se expandir também para as Escolas de Samba do grupo especial tradicionalmente controladas por banqueiros do bicho. Tal relação se exemplifica no caso do assassinato de Bid, morto ao voltar para sua residência após o desfile na Sapucaí, por associação com as facções de assassinos de aluguel formadas por milicianos ${ }^{25}$. Essa nova configuração da cúpula das escolas de samba foi liderada pelo ex-capitão do Bope Adriano Magalhães da Nóbrega, que tinha relações profundas com membros da família do banqueiro Maninho ${ }^{26}$. Os primeiros indícios de tal ligação com o carnaval teriam sido assegurados por ele nos últimos anos na tomada de poder em pelo menos duas escolas de samba, Salgueiro e Vila Isabel. Além de ser investigado no assassinato, em setembro de 2016, de Falcon, então presidente da Portela e subtenente reformado da PM. Os investigadores da Polícia Civil e do Ministério Público do Rio de Janeiro encontraram entre os pertences de Adriano dois crachás da LIESA, dos anos de 2016 e 2017, em que ele aparece como diretor da escola Vila Isabel, que dava livre acesso à pista nos desfiles da Sapucaí. Adriano era o braço direito do contraventor Bernardo Bello, acusado por Shanna de ser o mandante da tentativa de assassinato ocorrido contra ela no final de 2019, quando ele assumiu o controle da escola Vila Isabel. Ainda segundo a reportagem da Revista ÉPOCA (28 fev. 2020), essa nova dinâmica não seria um processo exclusivo de escolas do Grupo Especial. As escolas do Grupos de Acesso também estariam sofrendo com a ameaça e a tomada de diretorias por indicados de milicianos. Em junho de 2015, o presidente da União do Parque Curicica, Wagner Rafael de Souza, o Dádi, foi executado com tiros de pistola dentro de seu carro. Ele fora eleito apenas três meses antes e teria contrariado ordens da milícia sobre a agremiação. A suspeita pesou sobre o ex-PM Orlando Oliveira de Araújo, o miliciano Orlando Curicica. Um sobrevivente do ataque o apontou como um dos criminosos. Depois, em juízo, a testemunha voltou atrás. Com isso exposto, se torna cada vez mais evidente que a lucratividade e o prestígio das agremiações do carnaval carioca estão, recorrentemente, mais inseridos no radar dos grupos smilicianos, senão para dividi-las com bicheiros, tomá-las inteiramente, representando um controle total sobre seus territórios.

Já o fenômeno da privatização da segurança se diversifica em diversos aspectos quando observada pela relação entre esses dois grupos. Milicianos podem tanto fazer a segurança pes-

25 Um dos seguranças que estavam com Bid no momento de sua morte era o ex-PM expulso da corporação. Portal G1. (2020). Disponível em: https:/g1.globo.com/rj/rio-de-janeiro/noticia/2020/02/27/seguranca-de-contraventor-bid-e-ex-policial-expulso-da-pm-diz-policia.ghtml.

26 A escola de Samba Vila Isabel afirmou à Revista ÉPOCA (2020) que o credenciamento de Adriano foi feito a pedido de Myro Garcia, o Mirinho, filho de Maninho. Assim como o pai, e agora o tio, o jovem também foi assassinado, em 2017, ano da última credencial de Adriano. Segundo a Vila Isabel, Mirinho pôde pedir a credencial do miliciano porque era membro benemérito da escola. 
soal de determinados banqueiros do bicho, como produzir ataques a banqueiros concorrentes e a seus negócios. As batalhas travadas entre bicheiros envolvem a atuação de agentes da milícia tem cada vez mais ganhado as páginas dos principais noticiários do país como mais um desdobramento do complexo processo relacionado às atuais dinâmicas referentes à segurança pública no meio urbano carioca. Tais disputas criam um clima de inconstância temporária e incertezas no controle do jogo até que a ordem seja mais uma vez estabelecida, tudo isso para que as apostas possam continuar a fluir normalmente.

\section{CONCLUSÃOO}

Como foi dito inicialmente, o jogo do bicho, como uma categoria polissêmica adquire sentidos distintos a partir do ângulo de observação. Entendido como cultura, tradição, informalidade, mercado, vício, crime e diversas outras formas. Assim, o "Jogo do Bicho" (com letra maiúscula) se apresenta como uma forma que abarca todas essas características, sendo uma expressão de um fenômeno social altamente complexo, podendo ser entendido como um "fato social brasileiro.” (SOARES, 1993). Suas formas de gestão e regulação nas ruas tem por detrás uma base de sustentação pautada por uma organização entre atores que se encontram dentro e fora do Estado e do escopo legal de modo a permitir a continuidade do mercado de jogos e diversões ilegais, bem como o sustentáculo político, econômico e territorial dos atores envolvidos.

O lucro pode ser entendido como uma das formas com as quais tais controles são consolidados e um dos objetivos fins dos grupos abordados. Como afirmou a historiadora Amy Chazkel (2007, p 553), “A desobediência do jogo do bicho por parte dos 'banqueiros' é pautada pelos mesmos fins lucrativos dos opulentos industrialistas". Assim, banqueiros do bicho e milicianos utilizam dos grandes recursos adquiridos para ampliar cada vez mais seu poder frente a contravenção. A divisão territorial é assim pautada por uma incessante busca do monopólio do jogo dentro de certos limites de uma convivência "pacífica". Apesar disso, ficou evidente aqui que, apesar dos controles regulatórios impostos pelos próprios atores nesse campo disputas, conflitos armados são, e provavelmente continuarão a ser no futuro próximo, cada vez mais as formas de lidar, coibir ou, até mesmo, aniquilar a concorrência. A sorte no jogo, neste caso pode trazer azar na vida, haja vista a ininterrupta lista de conflitos com desfechos trágicos e mortíferos, tanto para o baixo como para o alto escalão dos que administram o jogo. A gestão da morte 
e a morte do concorrente não impede ou interrompe o processo de escalada da violência que vem se intensificando e, a cada dia mais e mais vezes exposto nos noticiários nacionais. Um verdadeiro "jornal da morte" com "um bicheiro assassinado em decúbito dorsal"27" eventualmente exibido nas páginas policiais.

A necessidade do aval ou do apadrinhamento de atores já inseridos no mercado de jogos da contravenção à entrada de novos atores impede que aventureiros possam explorar desse mercado por conta própria. Esta necessidade evidencia que a regulação deste mercado se dá de forma altamente controlada e regulada por relações de afinidade e parentesco, pautadas por valores hierárquicos e disciplinares oriundas das casernas do período da ditadura militar. Tais valores militarizados podem ser abordados como mais um dos pontos de intersecção entre bicheiro e milicianos que convergem para atuações com essências similares e coerentes entre si.

Como já dizia a canção de Dorival Caymmi: “Quem não gosta de samba, bom sujeito não é", e nesse caso, quem gosta aparentemente também não. A gestão do carnaval carioca apresenta dois lados antagônicos. Por um lado, de uma festa eufórica e contagiante, exportada para o mundo como um dos símbolos nacionais da cultura popular, e, por outro, adquire contornos obscuros em seus barracões. Como apontado aqui, pelo menos desde a década de 1960, estiveram controladas e aparelhadas por banqueiros da loteria do bicho e parasitadas por agentes do Estado que buscam consolidar, em meio a expressão cultural carnavalesca, o prestígio e o reconhecimento popular das regiões onde os preparativos do espetáculo são produzidos e criados. Além disso, com a crescente popularidade do desfile, buscam angariar cada vez mais recursos e poder político na sociedade carioca como um todo. Evidências de que tanto banqueiros do bicho como milicianos dançam conforme a mesma música.

\section{REFERÊNCIAS}

1. ALVES, José Cláudio Souza. Dos barões ao extermínio: uma história da violência na Baixada Fluminense. Duque de Caxias: APPH: Clio, 2003.

2. BEZERRA, Luiz Anselmo. A família Beija-Flor. 2010. Dissertação (Mestrado em História) - Programa de Pós-Graduação em História, Universidade Federal Fluminense, Niterói.

27 Letra do Samba "Jornal da morte". 
3. CANO, Ignácio; DUARTE, Thais. No sapatinho, a evolução das milícias no Rio de Janeiro [2008 -2011]. Rio de Janeiro: LAV Fundação Heinrich Boll, 2012.

4. CAVAlCANTI, Maria Laura Viveiros de Castro. Le Mécénat du jogo do bicho dans. Le carnaval de Rio de Janeiro. In: JORNADA DE CIÊNCIAS SOCIAIS, São Paulo: UNESP, 1994.

5. CHAZKEL, Amy. Leis da sorte: O jogo do bicho e a construção da vida pública urbana. Campinas: Ed. UNICAMP, 2014.

6. CHINELLI, Filipina.; SILVA, Luiz Antônio Machado da. O vazio da ordem: Relações políticas e organizacionais entre escolas de samba e o jogo do bicho. Revista do Rio de Janeiro, Rio de Janeiro UERJ/CEP, v. 1, n. 5, p. 42-52, 1993. Disponível em: http:// www.forumrio.uerj.br/documentos/revista_12/12_mediacoes_FilippinaChinelli.pdf. Acesso em: 03 mar. 2020.

7. DAMATTA, Roberto; SOÁREZ, Elena. Águias, Burros e Borboletas, um estudo antropológico do jogo do bicho. Rio de Janeiro: Rocco, 1999.

8. DE SOTO, Hernando de. El otro sandero. Lima: Ed Instituto Libertad y Democracia, 1980.

9. FOUCAULT, Michel. Des supplices aux cellules. In: FOUCAULT, Michel. Dits et écrits II. Paris: Gallimard, 1994, p. 716-720.

10. FOUCAULT, Michel. História da sexualidade I. A vontade de saber. Rio de Janeiro: Edições Graal, 2001.

11. FOUCAUlT, Michel. Vigiar e Punir: nascimento da prisão. 34. ed. Petrópolis: Ed. Vozes, 2007.

12. GLUCKMAN, Max. Análise de uma situação social na Zululândia moderna. (1958). In: FELDMAN-BIANCO, Bela. Antropologia das sociedades complexas. São Paulo: UNESP, 2010.

13. LABRONICI, Rômulo Bulgarelli. Para Todos, vale o escrito: uma etnografia do jogo do bicho. 2012. Dissertação (Mestrado em Antropologia) - Programa de Pós-Graduação em Antropologia, Universidade Federal Fluminense, Niterói.

14. LABRONICI, Rômulo Bulgarelli; SILVA, Gabriel Borges da. Uma contravenção controvertida: reflexões acerca da tutela penal do jogo do bicho. Revista Interdisciplinar de Direito, Faculdade de Direito de Valença, v. 14, n. 1, pp.201-213 jan./jun. 2017. Disponível em: http://revistas.faa.edu.br/index.php/FDV/ article/download/257/205/. Acesso em: 05 mar. 2020.

15. MAGALHÃES, Felipe Santos. Ganhou, Leva! O jogo do bicho no Rio de Janeiro (1989-1960). Rio de Janeiro: Ed. FGV, 2011.

16. MISSE, Michel. Malandros, Marginais e Vagabundos e a Acumulação Social 
da Violência no Rio de Janeiro. 1999. Tese (Doutorado em Sociologia) - Instituto Universitário de Pesquisas do Rio de Janeiro, Rio de Janeiro.

17. MISSE, Michel. Mercados Ilegais, redes de proteção e organização local do crime no Rio de Janeiro. Estudos Avançados, São Paulo, v. 21, n. 61, p. 139-157 2007. Disponível em: https://www.scielo.br/scielo.php?pid=S0103-40142007000300010 \&script=sci abstract\&tlng=pt. Acesso em: 02 mar. 2020.

18. OTÁVIO, Chico; JUPIARA, Aloy. Os porões da contravenção: Jogo do bicho e ditadura militar: a história da aliança que profissionalizou o crime organizado. Rio de Janeiro: Record, 2015.

19. PIRES, Lenin. Esculhamba, mas não esculacha! Uma etnografia dos usos urbanos dos trens da Central do Brasil. Niterói: EdUFF, 2011.

20. RABOSSI, Fernando. Nas ruas de Ciudad Del Este: vidas e vendas num mercado de fronteira. 2004. Tese (Doutorado em Antropologia Social) - Programa de Pós-Graduação em Antropologia Social do Museu Nacional, Universidade Federal do Rio de Janeiro, Rio de Janeiro.

21. RODRIGUES, Nelson. Boca de Ouro: tragédia carioca em três atos. Rio de Janeiro: Nova Fronteira, 1959.

22. SOARES, Simone Simões Ferreira. Jogo do bicho: a saga de um fato social brasileiro. Rio de Janeiro: Bertrand Brasil, 1993.

23. SOÁREZ, Elena. Jogo do bicho, um totemismo carioca. 1992. Dissertação (Mestrado em Antropologia Social) - Programa de Pós-Graduação em Antropologia Social, Museu Nacional, Universidade Federal do Rio de Janeiro, Rio de Janeiro.

24. TELLES, Vera da Silva. Nas dobras do legal e do ilegal: Ilegalismos e jogos de poder nas tramas da cidade. Dilemas: Revista de Estudos de Conflito e Controle Social, v. 2, p. 97-126, 2009. Disponível em: https://revistas.ufrj.br/index.php/dilemas/article / view/7192. Acesso em: 10 mar. 2020

\section{Rômulo Bulgarelli Labronici}

Pós-Doutorado em Antropologia pelo Programa de Pós-Graduação em Antropologia da Universidade Federal Fluminense, Doutor e Mestre em Antropologia pelo Programa de PósGraduação em Antropologia da Universidade Federal Fluminense. Pesquisador do Instituto de Estudos Comparados em Administração Institucional de Conflitos (INCT/InEAC) e do Laboratório de Estudos sobre Conflito, Cidadania e Segurança Pública. ID ORCID: http://orcid. org/0000-0002-9860-0244. E-mail: romulolabronici@gmail.com. 